\title{
Study of wave forces acting on the box- girder superstructure of coastal bridges in the submerged condition based on potential flow theory
}

Bo Huang ${ }^{1,2^{*}}$, Qingyang Ren ${ }^{1,2}$, Xiaolu Cui ${ }^{3}$, Jiawei Zhang ${ }^{4}$ and Bing Zhu ${ }^{4}$

*Correspondence: bohuang@cqjtu. edu.cn

${ }^{1}$ State Key Laboratory of Mountain Bridge and Tunnel Engineering, Chongqing Jiaotong University, Chongqing 400074, China

${ }^{2}$ School of Civil Engineering, Chongqing Jiaotong University, Chongqing 400074, China Full list of author information is available at the end of the article

\begin{abstract}
The box-girder superstructure of coastal bridges is vulnerable to wave-induced damage in the case of small clearances. The analytical method for estimating the wave forces on the box-girder superstructure of coastal bridges is proposed based on the potential flow theory in this paper. The two-dimension problem of the boxgirder superstructure under the wave action is defined with some necessary simplifications first. Then, the analytical solutions are solved by the eigenfunction matching method, and the wave force on the submerged box-girder superstructure is calculated using the Bernoulli principle. After validating the accuracy of the proposed method by previous calculations and the experimental test, the influences of the girder type and structural configuration on the wave forces of submerged box-girder are conducted using the proposed analytical method. The results show that the girder type has a significant effect on the wave forces of the submerged superstructure, and the influence of various structural parameters should be considered comprehensively in the structural safety design under wave actions. The results of the present study can provide a useful reference for the estimation of wave forces and the structural design of the box-girder superstructure of coastal bridges.
\end{abstract}

Keywords: Coastal bridge, Box-girder superstructure, Wave forces, Analytical method

\section{Introduction}

With the continuous development of coastal traffic engineering and the frequent occurrence of marine disasters in recent years, the wave force has become the control load of coastal bridges. During Hurricane Ivan in 2004, India Ocean Tsunami in 2004, Hurricane Katrina in 2005, and Great Japan Tsunami in 2011, extensive damages to coastal bridges near the seacoast occurred under the combination of extreme waves and huge water level rise (Yeh et al. 2007; Shoji and Moriyama 2007; Douglass and Krolak 2008; Bricker and Nakayama 2014; Motley et al. 2015). Due to the complexity of the wave-bridge interactions, the estimation of wave forces on the coastal bridge superstructures draws the attention of many engineers and researchers in recent years.

(c) The Author(s). 2020 Open Access This article is licensed under a Creative Commons Attribution 4.0 International License, which permits use, sharing, adaptation, distribution and reproduction in any medium or format, as long as you give appropriate credit to the original author(s) and the source, provide a link to the Creative Commons licence, and indicate if changes were made. The images or other third party material in this article are included in the article's Creative Commons licence, unless indicated otherwise in a credit line to the material. If material is not included in the article's Creative Commons licence and your intended use is not permitted by statutory regulation or exceeds the permitted use, you will need to obtain permission directly from the copyright holder. To view a copy of this licence, visit http://creativecommons.org/licenses/by/4.0/. 
The mechanics of wave-bridge interactions have been investigated using experimental tests by many researchers. The wave forces obtained from experimental tests can fully consider the complex structural geometries, wave breakings, and two-phase flow interactions during the wave-bridge interactions. The I-10 coastal bridge over the Mobile Bay was selected as the prototype model to conduct a 1:10 scaled experimental test in the wave flume by Cuomo et al. (2009), and the wave forces on this bridge model were measured to investigate the influence of the entrapped air. The damaged coastal bridge was designed as a reinforced concrete model to consider the dynamic responses of coastal bridge superstructures under wave actions in the study of Bradner et al. (2011). The springs were used in their experimental tests to obtain various stiffnesses of the horizontal support system, and the dynamic properties of the bridge system were investigated under regular and random wave conditions with multiple clearances. 1:10 scaled experimental tests were conducted by Guo et al. (2015a) to study the quasi-static and slamming wave forces on the bridge superstructure with the T-type girder. The effect of water levels, wave heights, wave periods, the existence of the substructure and neighboring segments were determined in their study. To investigate the effect of the entrapped air and air vents on the wave forces of coastal bridge superstructures, many experimental tests were conducted on T-type girders (Seiffert et al. 2014; Istrati et al. 2016; Istrati et al. 2017). In recent years, the wave forces on the commonly used boxgirder superstructures for long-span coastal bridges have become a hot topic in current research with the development of coastal engineering for the Western Pacific region (Hayashi 2013; Huang et al. 2018a; Huang et al. 2019b). The experimental tests conducted by Huang et al. (2018a) for the wave forces on the box-girder superstructure show the significant differences between the wave forces of the two type girders (boxgirder and T-type girder). Their results show that due to the wave blocking effect on the front empty part of the box-girder, the vertical uplift force on the box girder deck larger than that on the T-type girder deck. Based on the solitary wave tests on the boxgirder superstructures, Huang et al. (2019b) study the vulnerability assessment of the box-girder superstructure by comparing wave forces with superstructure's capacities. They found that impulsive wave force on box-girder is significant for elevated conditions and failure probability of coastal bridge superstructure subjected to extreme wave conditions will be effectively reduced by increasing the horizontal and vertical resistance of the bridge superstructure.

With the development of computer and numerical methods, numerical simulations of wave-bridge interactions have been conducted by many researchers in recent years. In the case of wave-bridge interactions, the Reynolds-averaged Navier-Stokes (RANS) equations combine with the volume of fluid (VOF) method are used extensively for two-phase flow simulations (Xiao et al. 2010; Hayatdavoodi et al. 2014; Motley et al. 2016; Xu et al. 2016a; Xu et al. 2017), and the mass-spring-damper system is implemented with commercial program Fluent to consider the structural vibrations (Xu and Cai 2015; Xu and Cai 2017). The wave-current interactions (Qu et al. 2018; Huang et al. 2018b), the effect of inclinations of the deck (Xu and Cai 2014; Motley et al. 2015), the effect of submersion depth (Huang et al. 2019a; Qu et al. 2020) and the accuracy of particle finite element method in simulating the wave forces on bridge superstructures (Zhu et al. 2018) were comprehensively studied using numerical methods. 
However, both experimental tests and numerical calculations require the necessary test site or large computing equipment, and the professional foundation and operational experience of relevant personnel are also needed. Therefore, highly efficient computational methods and empirical equations for estimating the wave forces on the coastal bridge superstructures are the key research directions in recent years. Based on the experimental results and numerical simulations, many empirical equations were proposed to calculate the wave forces on various types of superstructures. Douglass et al. (2006) and McPherson (2008) proposed the wave forces on the deck and T-type girder using the hydrostatic method based on the previous observations and experimental tests. Xu et al. (2016b) further extended the hydrostatic method of McPherson (2008) by adding a hydrodynamic force component into the total force on the T-type girder superstructures. Based on the experimental tests of wave forces on the box-girder superstructure and the empirical equation proposed by $\mathrm{Xu}$ et al. (2016b), Huang et al. (2018a) took the blocking effect of box-girder during the wave-bridge interactions into consideration and proposed an empirical method to estimate the maximum wave forces on box-girder. These empirical equations are mostly based on experimental tests and numerical simulation results and only aim at some wave parameters, specific structural forms, or several submerged states, which cannot guarantee the accuracy of estimation results beyond the application scope. Thus, the classic method named potential flow theory that used to analyze the wave properties and wave forces for the structure under gravity waves was introduced by Guo et al. (2015b) to estimate the wave forces on the T-type girder superstructures. The accuracy and efficiency of the proposed analytical method were validated using two large scale experimental tests in their study. Fang et al. (2018) further extend the potential flow theory to predict the wave forces on the T-type girder superstructures under oblique wave action. The effects of wave propagation direction, wave properties, and structural configuration were investigated using the proposed analytical method, and the accuracy of the proposed method was validated by an oblique wave test of a 1:10 scaled bridge model (Fang et al. 2019a). The research conducted by Fang et al. (2019b) also proved that the potential flow theory is also accurate and efficient in calculating the focused wave force on submerged plates. Previous literature has indicated that the differences of wave forces on the box-girder bridges and T-girder bridges are quite different, thus whether the potential flow theory can be used to accurately calculate the wave force on the boxgirder superstructures is worth exploring (Huang et al. 2018a). And the potential flow theory is utilized to further estimate the wave forces on box-girder superstructures and investigate the effect of girder type and structural configuration on wave forces.

In this study, the mathematical formulation for the two-dimension boundary value problem is introduced first. Then, the accuracy and efficiency of the proposed method are validated by two comparisons, including the classical problem studied by Mei and Black (1969) and the hydrodynamic experiment on the boxgirder superstructure. Finally, the influences of the girder type and structural configuration on the wave forces of the box-girder superstructures are conducted using the proposed method. 


\section{Mathematical formulation}

\subsection{Problem definitions}

With the construction and development of long-span bridges, the superstructure of coastal bridges adopted in recent years is the box-girder type. The superstructure of this type of bridge has a large cross-section size, which is different from the T-type girder in the previous studies. In recent years, the research on the extreme wave force of the box-girder bridge also shows that the force of the two structures under extreme wave action has a great difference (Huang et al. 2018a; Huang et al. 2019a). The T-type girder is always connected by a diaphragm, and the box-girder bridge is a combination of the box chamber and the bridge deck, which has greater rigidity than the T-type bridge. In the present study, the potential flow theory is used to establish the model for a box-girder bridge superstructure under the action of wave forces in a submerged state, which is simplified as a boundary value problem (shown in Fig. 1).

For the convenience and efficiency of the method, the wave is simplified as an inviscid, incompressible, and irrotational material. Therefore, the wave breakings, air capture, and impulse effect are neglected in the proposed model. This simplification is reasonable by the fact that the box-girder investigated in the present study is under submerged conditions, and the impulse action and wave breakings for this situation is relatively small. With the high rigidity of the box-girder superstructure, the superstructure is assumed to be a rigid body. Therefore, wave-structure interaction is not discussed in the present study. The effect of the angle of the web and flange of the boxgirder is assumed to be small, thus the upper flange and web of the box-girder are simplified as vertical edges. The simplified section of the box-girder is shown in Fig.1. Because the inclination of each part of the box girder is small and close to the vertical edges, the wave force caused by the angle changes of the web and flange of the boxgirder superstructure can be ignored.

At present, the box-girder superstructure of the coastal bridge is usually made of prestressed concrete and has a large span, the wave-structure system can be simplified to a two-dimensional problem (Guo et al. 2015b; Fang et al. 2018; Huang et al. 2018a). The proposed method assuming that the shape of the section remains the same along the span of the bridge, and the incident wave is assumed to be a linear regular wave and its

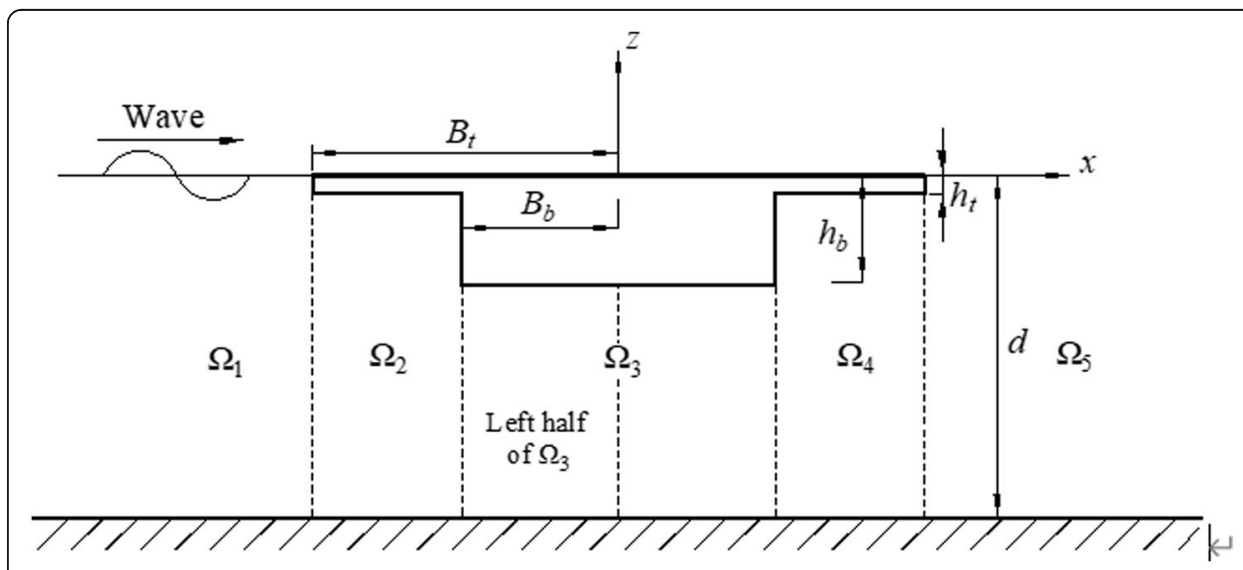

Fig. 1 Schematic of the boundary value problem for wave and box -girder system 
propagation direction is perpendicular to the direction of the bridge span. The schematic diagram used in the present study is shown in Fig. 1, and the Cartesian coordinate origin is defined at the top center of the bridge deck. The $\mathrm{x}$-axis in the Cartesian coordinate system is consistent with the transverse direction of the box-girder bridge and overlaps with the still water level. As shown in Fig. 1, the entire domain is divided into five subdomains according to the boundary of the web and flange edges of the box-girder superstructure. The wave propagates from the offshore region $\Omega_{1}$ to the vicinity of the box-girder and then interacts with the structure $\left(\Omega_{2}, \Omega_{3}\right.$, and $\left.\Omega_{4}\right)$ and propagates to the inshore region $\Omega_{5}$, and the offshore subdomain $\Omega_{1}$ and inshore subdomain $\Omega_{5}$ are assumed to be an infinite region for simplicity and efficiency.

The two-dimensional potential flow theory is used to solve the wave forces on the box-girder superstructure. For the periodic problems caused by ocean waves, the time factor can be separated, and the velocity potential can be expressed as:

$$
\Phi(x, z, t)=\operatorname{Re}\left[\phi(x, z) e^{-i \omega t}\right]
$$

where $R e$ represents to take the real part of the expression, $\omega$ is the angular frequency of the incident wave and $t$ is the time. The space velocity potential function of the flow field $\phi(x, z)$ should satisfy the Laplace governing equation:

$$
\frac{\partial^{2} \phi(x, z)}{\partial x^{2}}+\frac{\partial^{2} \phi(x, z)}{\partial z^{2}}=0
$$

Besides, the velocity potentials also need to satisfy the following boundary conditions:

1) Linearized free surface condition:

$$
\frac{\partial \phi(x, z)}{\partial z}=\frac{\omega^{2}}{g} \phi(x, z) \quad\left(|x| \geq B_{t}, z=0\right)
$$

where $g$ represents the gravity acceleration and $B_{t}$ denotes half the width of the bridge deck.

2) Seabed boundary condition:

$$
\frac{\partial \phi(x, z)}{\partial z}=0 \quad z=-d
$$

in which the $d$ is the water depth.

3) Top flange boundary conditions:

$$
\frac{\partial \phi(x, z)}{\partial z}=0 \quad\left(B_{b} \leq|x| \leq B_{t}, z=-h_{t}\right)
$$




$$
\frac{\partial \phi(x, z)}{\partial x}=0 \quad\left(|x|=B_{t},-h_{t} \leq z \leq 0\right)
$$

where $B_{b}$ represents half the width of the bridge girder and $h_{t}$ is the height of the bridge deck.

4) Web surface boundary conditions:

$$
\begin{array}{ll}
\frac{\partial \phi(x, z)}{\partial z}=0 & \left(|x| \leq B_{b}, z=-h_{b}\right) \\
\frac{\partial \phi(x, z)}{\partial x}=0 & \left(|x|=B_{b},-h_{b} \leq z \leq-h_{t}\right)
\end{array}
$$

in which the $h_{b}$ is the height of the box-girder superstructure.

Furthermore, the flow fluids in the interior subdomains $\left(\Omega_{2}, \Omega_{3}\right.$, and $\left.\Omega_{4}\right)$ are interconnected, and the velocity potentials and the horizontal velocities need to satisfy the continuity condition at the junction of the subdomains,

$$
\begin{aligned}
& \phi_{j}(x, z)=\phi_{j+1}(x, z) \quad(j=2,3) \\
& \frac{\phi_{j}(x, z)}{\partial x}=\frac{\phi_{j+1}(x, z)}{\partial x} \quad(j=2,3)
\end{aligned}
$$

\subsection{Analytical solution}

The classical solution is solving the velocity potential using the eigenfunction expansion method in different subdomains, and the equations of solving unknown coefficients are established by combining different boundary conditions. Mei and Black (1969) simplified the wave reflection and projection problems of square box structure by decomposing them into positive symmetric and antisymmetric problems. In this study, the velocity potential is decomposed into symmetric potential $\phi^{\mathrm{s}}$ and antisymmetric potential $\phi^{\mathrm{a}}$ using the proposed method. The velocity potential function satisfies the following characteristics:

$$
\begin{aligned}
& \phi(x, z)=\left[\phi^{\mathrm{s}}(x, z)+\phi^{\mathrm{a}}(x, z)\right] / 2 \\
& \phi^{\mathrm{s}}(x, z)=\phi^{\mathrm{s}}(-x, z) \\
& \phi^{\mathrm{a}}(x, z)=-\phi^{\mathrm{a}}(-x, z)
\end{aligned}
$$

The method can limit the calculation region to half of the region $(x<0)$ to solve the problem, and the symmetric and antisymmetric solutions are solved respectively as follow.

\section{(1) Symmetric solutions}

The symmetric velocity potentials of limit subdomains $\left(\Omega_{1}, \Omega_{2}\right.$, and left half of $\left.\Omega_{3}\right)$ can be determined by the eigenfunction expansion method and corresponding boundary conditions: 


$$
\begin{aligned}
& \phi_{1}^{\mathrm{s}}(x, z)=-\frac{i g A}{\omega}\left[\left(e^{i k_{0}\left(x+B_{t}\right)}+A_{0}^{\mathrm{s}} e^{-i k_{0}\left(x+B_{t}\right)}\right) Z_{0}\left(k_{0} z\right)+\sum_{n=1}^{\infty} A_{n}^{\mathrm{s}} e^{k_{n}\left(x+B_{t}\right)} Z_{n}\left(k_{n} z\right)\right] \\
& \phi_{2}^{\mathrm{s}}(x, z)=-\frac{i g A}{\omega}\left[B_{10}^{\mathrm{s}} Y_{10}\left(\lambda_{10} z\right)+\sum_{n=1}^{\infty} B_{1 n}^{\mathrm{s}} \frac{\cosh \lambda_{1 n} x}{\cosh \lambda_{1 n} B_{t}} Y_{1 n}\left(\lambda_{1 n} z\right)\right] \\
& \phi_{3}^{\mathrm{s}}(x, z)=-\frac{i g A}{\omega}\left[B_{20}^{\mathrm{s}} Y_{20}\left(\lambda_{20} z\right)+\sum_{n=1}^{\infty} B_{2 n}^{\mathrm{s}} \frac{\cosh \lambda_{2 n} x}{\cosh \lambda_{2 n} B_{b}} Y_{2 n}\left(\lambda_{2 n} z\right)\right]
\end{aligned}
$$

where $\mathrm{A}$ is the amplitude of the incident wave; $A \mathrm{~S} \mathrm{n}, B \mathrm{~S} 1 n$, and $B \mathrm{~S} 2 n$ is the unknown coefficient of symmetric velocity potential for subdomains $\Omega_{1}, \Omega_{2}$, and left half of $\Omega_{3}$, respectively. $Z_{n}\left(k_{n} z\right), Y_{1 n}\left(\lambda_{1 n} z\right)$ and $Y_{2 n}\left(\lambda_{2 n} z\right)$ is the vertical eigenfunctions in subdomains $\Omega_{1}, \Omega_{2}$ and left half of $\Omega_{3}$, respectively, which can be expressed as:

$$
\begin{aligned}
& Z_{n}\left(k_{n} z\right)=\left\{\begin{array}{cc}
\cosh k_{0}(z+d) / \cosh k_{0} d \\
\cos k_{n}(z+d) / \cos k_{n} d
\end{array}(n=1,2, \cdots)\right. \\
& Y_{1 n}\left(\lambda_{1 n} z\right)=\left\{\begin{array}{cc}
\sqrt{2} / 2 & (n=0) \\
\cos \lambda_{1 n}(z+d) & (n=1,2, \cdots)
\end{array}\right. \\
& Y_{2 n}\left(\lambda_{2 n} z\right)=\left\{\begin{array}{cc}
\sqrt{2} / 2 & (n=0) \\
\cos \lambda_{2 n}(z+d) & (n=1,2, \cdots)
\end{array}\right.
\end{aligned}
$$

in which the $k_{0}$ and $k_{n}$ are the corresponding wave numbers solving by dispersion equation.

$$
\omega^{2}=\left\{\begin{array}{l}
g k_{0} \tanh k_{0} d \\
-g k_{n} \tanh k_{n} d \quad(n=1,2, \cdots)
\end{array}\right.
$$

$\lambda_{1 n}$ and $\lambda_{2 n}$ can be determined by solving the following equations:

$$
\begin{aligned}
& \lambda_{1 n}=n \pi /\left(d-h_{t}\right) \quad(n=0,1,2, \cdots) \\
& \lambda_{2 n}=n \pi /\left(d-h_{b}\right) \quad(n=0,1,2, \cdots)
\end{aligned}
$$

The vertical eigenfunctions $Z_{n}\left(k_{n} z\right), Y_{1 n}\left(\lambda_{1 n} z\right)$ and $Y_{2 n}\left(\lambda_{2 n} z\right)$ all satisfy the orthogonality relationship in their corresponding subdomain:

$$
\begin{aligned}
& \int_{-d}^{0} Z_{m}\left(k_{m} z\right) Z_{n}\left(k_{n} z\right) \mathrm{d} z=\left\{\begin{array}{cc}
0 & (m \neq n) \\
\left(d / 2+\sinh 2 k_{0} d / 4 k_{0}\right) / \cosh ^{2} k_{0} d & (m=n=0) \\
\left(d / 2+\sinh 2 k_{m} d / 4 k_{m}\right) / \cosh ^{2} k_{m} d & (m=n \neq 0)
\end{array}\right. \\
& \int_{-d}^{-h_{t}} Y_{1 m}\left(\lambda_{1 m} z\right) Y_{1 n}\left(\lambda_{1 n} z\right) \mathrm{d} z=\left\{\begin{array}{cc}
0 & (m \neq n) \\
\left(d-h_{t}\right) / 2 & (m=n)
\end{array}\right. \\
& \int_{-d}^{-h_{b}} Y_{2 m}\left(\lambda_{2 m} z\right) Y_{2 n}\left(\lambda_{2 n} z\right) \mathrm{d} z=\left\{\begin{array}{cc}
0 & (m \neq n) \\
\left(d-h_{b}\right) / 2 & (m=n)
\end{array}\right.
\end{aligned}
$$

At the interfaces of $x=-B_{t}$, the continuity conditions in Eqs. $(9,10)$ can be substituted into Eqs. $(14,15)$, and integrating the equation related to vertical water depth $z$ from $z=-d$ to $z=-h_{t}$ to obtain the linear equations by truncating $n$ to $N$ :

$$
\left[f_{n}^{s}\right]_{N+1}+\left[a_{n m}^{s}\right]_{(N+1) \times(N+1)}\left\{A_{n}^{\mathrm{s}}\right\}_{N+1}=\left\{B_{1 n}^{\mathrm{s}}\right\}_{N+1}
$$




$$
\left[e_{n}^{s}\right]_{N+1}+\left\{A_{n}^{\mathrm{s}}\right\}_{N+1}=\left[b_{m n}^{s}\right]_{(N+1) \times(N+1)}\left\{B_{1 n}^{\mathrm{s}}\right\}_{N+1}
$$

where the detailed formulations of $f_{n}^{s}, a_{n m}{ }^{s}, e_{n}^{s}$, and $b_{m n}{ }^{s}$ can be found in the Appendix.

At the interfaces of $x=-B_{b}$, the continuity conditions Eqs. $(9,10)$ can be substituted into Eqs. $(15,16)$, and integrating the equation related to vertical water depth $z$ from $z=-d$ to $z=-h_{b}$ to obtain the linear equation by truncating $n$ to $N$ :

$$
\left[c_{m m}^{s}\right]_{(N+1) \times(N+1)}\left\{B_{1 n}{ }^{s}\right\}_{N+1}=\left\{B_{2 n}{ }^{s}\right\}_{N+1}
$$

$A S \mathrm{n}$ and $B \mathrm{~S} 1 n$ can be calculated from Eqs. $(26,27)$, and then the $B S 2 n$ can be obtained by substituting $B S 1 n$ into Eq. (28).

\section{(2) Antisymmetric solutions}

Based on the antisymmetric solution and corresponding boundary conditions, the antisymmetric velocity potentials are obtained by solving the Laplace governing equation in Eq. (2) for limit subdomains $\left(\Omega_{1}, \Omega_{2}\right.$ and left half of $\left.\Omega_{3}\right)$ :

$$
\begin{aligned}
& \phi_{1}^{\mathrm{a}}(x, z)=-\frac{i g A}{\omega}\left[\left(e^{i k_{0}\left(x+B_{t}\right)}+A_{0}^{\mathrm{a}} e^{-i k_{0}\left(x+B_{t}\right)}\right) Z_{0}\left(k_{0} z\right)+\sum_{n=1}^{\infty} A_{n}^{\mathrm{a}} e^{k_{n}\left(x+B_{t}\right)} Z_{n}\left(k_{n} z\right)\right] \\
& \phi_{2}^{\mathrm{a}}(x, z)=-\frac{i g A}{\omega}\left[B_{10}^{\mathrm{a}} \frac{x}{B_{t}} Y_{10}\left(\lambda_{10} z\right)+\sum_{n=1}^{\infty} B_{1 n}^{\mathrm{a}} \frac{\sinh \lambda_{1 n} x}{\sinh \lambda_{1 n} B_{t}} Y_{1 n}\left(\lambda_{1 n} z\right)\right] \\
& \phi_{3}^{\mathrm{a}}(x, z)=-\frac{i g A}{\omega}\left[B_{20}^{\mathrm{a}} \frac{x}{B_{b}} Y_{20}\left(\lambda_{20} z\right)+\sum_{n=1}^{\infty} B_{2 n}^{\mathrm{a}} \frac{\sinh \lambda_{2 n} x}{\sinh \lambda_{2 n} B_{b}} Y_{2 n}\left(\lambda_{2 n} z\right)\right]
\end{aligned}
$$

Similarly, the equations of the unknown coefficients are calculated at the interfaces of $x=-B_{t}$ and $x=-B_{b}$ by substituting velocity potentials Eqs. (29) to (31) into the continuity conditions Eqs. $(9,10)$. Then, through multiplying by the vertical eigenfunctions and integrating the equations related to the water depth of the subdomains, three sets of linear equations can be achieved by truncating $n$ to $N$ :

$$
\begin{aligned}
& {\left[f_{n}^{a}\right]_{N+1}+\left[a_{n m}^{a}\right]_{(N+1) \times(N+1)}\left\{A_{n}^{\mathrm{a}}\right\}_{N+1}=\left\{B_{1 n}^{\mathrm{a}}\right\}_{N+1}} \\
& {\left[e_{n}^{a}\right]_{N+1}+\left\{A_{n}^{\mathrm{a}}\right\}_{N+1}=\left[b_{m n}^{a}\right]_{(N+1) \times(N+1)}\left\{B_{1 n}^{\mathrm{a}}\right\}_{N+1}} \\
& {\left[c_{m n}^{a}\right]_{(N+1) \times(N+1)}\left\{B_{1 n}^{\mathrm{a}}\right\}_{N+1}=\left\{B_{2 n}^{\mathrm{a}}\right\}_{N+1}}
\end{aligned}
$$

where the detailed formulations of $f_{n}{ }^{a}, a_{n m}{ }^{a}, e_{n}{ }^{a}, b_{m n}{ }^{a}$, and $c_{m n}{ }^{a}$ can be found in the Appendix.

The unknown coefficients $A S \mathrm{n}, B S 1 n$, and $B S 2 n$ for the antisymmetric solutions of velocity potentials are obtained by solving these three sets of linear equations Eqs. (32) to (34).

After obtaining the symmetric and antisymmetric solutions of velocity potentials in offshore subdomain $\Omega_{1}$, the reflection coefficient $R$ and the transmission coefficient $T$ of this subdomain can be calculated as follows:

$$
R=\left(R_{\mathrm{s}}+R_{\mathrm{a}}\right) / 2=\left(A_{0}^{\mathrm{s}}+A_{0}^{\mathrm{a}}\right) / 2
$$




$$
T=\left(R_{\mathrm{s}}-R_{\mathrm{a}}\right) / 2=\left(A_{0}^{\mathrm{s}}-A_{0}^{\mathrm{a}}\right) / 2
$$

which following the energy conservation condition:

$$
|R|^{2}+|T|^{2}=1
$$

The horizontal and vertical wave forces on the box-girder superstructure can be obtained by integrating the pressure along the surface of the structure using the linear Bernoulli equation:

$$
\begin{aligned}
& \begin{aligned}
F_{H}(t)=\iint_{S} p n_{x} e^{-i \omega t} d S=i \omega \rho\left[\int_{-h_{t}}^{0} \phi\left(-B_{t}, z\right) d z+\int_{-h_{b}}^{-h_{t}} \phi\left(-B_{b}, z\right) d z\right. \\
\left.\quad-\int_{-h_{t}}^{0} \phi\left(B_{t}, z\right) d z-\int_{-h_{b}}^{-h_{t}} \phi\left(B_{b}, z\right) d z\right] e^{-i \omega t} \\
=i \omega \rho\left[\int_{-h_{t}}^{0} \phi_{1}^{\mathrm{a}}\left(-B_{t}, z\right) d z+\int_{-h_{b}}^{-h_{t}} \phi_{2}^{\mathrm{a}}\left(-B_{b}, z\right) d z\right] e^{-i \omega t} \\
F_{V}(t)=\iint_{S} p n_{z} e^{-i \omega t} d S=i \omega \rho\left[\int_{-B_{t}}^{B_{t}} \phi\left(x,-h_{t}\right) d x+\int_{-B_{b}}^{B_{b}} \phi\left(x,-h_{b}\right) d x\right] e^{-i \omega t} \\
=i \omega \rho\left[\int_{-B_{t}}^{-B_{b}} \phi_{2}^{\mathrm{s}}\left(x,-h_{t}\right) d x+\int_{-B_{b}}^{0} \phi_{3}^{\mathrm{s}}\left(x,-h_{b}\right) d x\right] e^{-i \omega t}
\end{aligned}
\end{aligned}
$$

In which the $F_{H}$ and $F_{V}$ are the horizontal and vertical wave forces on the box-girder superstructure, respectively, $p$ is the pressure on the surface of the box-girder superstructure and $\rho$ represents the water density.

\section{Model validation}

Two comparisons are conducted to validate the efficiency and accuracy of the proposed method, including the classical problem studied by Mei and Black (1969) and the hydrodynamic experiment on the box-girder superstructure investigated by Zhang et al. (2020). The first one is the wave action on the rectangle structure, and the rectangular structure can be considered as a special form of the box-girder superstructure with $h_{t}=$ $h_{b}$ and $B_{t}=B_{b}$. The proposed method is implemented using Matlab and by truncating the infinite series order at $n=N$. The influences of the evanescent modes in the velocity potentials (Eqs. (14-16, 29-31)) on the accuracy and efficiency of the analytical solutions are investigated firstly. In this case, the box-girder superstructure is simplified as a rectangular structure with $h_{t}=h_{b}=0.09 \mathrm{~m}, B_{t}=B_{b}=0.25 \mathrm{~m}$, and $d=0.713 \mathrm{~m}$. Figure 2 shows the influence of the evanescent mode on nondimensional horizontal and vertical wave forces on the rectangular structure. As can be seen in Fig. 2, the non-dimensional vertical wave forces decrease with the increases of $k_{0} B_{t}$ and the horizontal wave forces increases first when $k_{0} B_{t}<1.2$ and then decreases with the increase of $k_{0} B_{t}$. In the present study, $k_{0} B_{t}$ represents the wave number coefficient related to the wave period. The influence of the evanescent mode on nondimensional wave forces in Fig. 2 shows that the calculation results are unstable when the evanescent mode is smaller than 3. It is shown that the non-dimensional vertical wave forces gradually converge to stable values when the truncation order large than 3 , and the nondimensional horizontal wave 

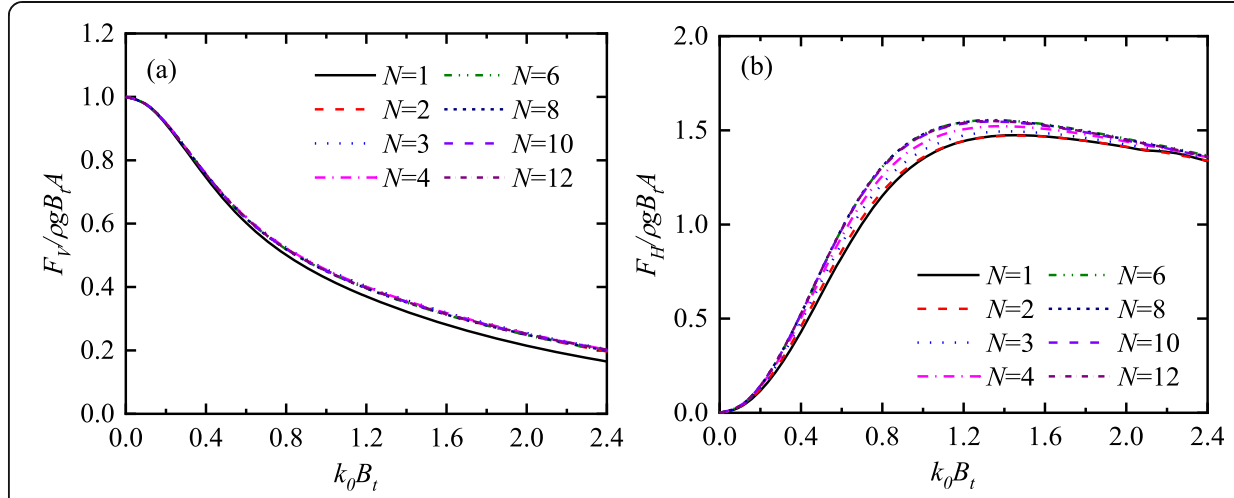

Fig. 2 Influence of the evanescent mode on the non-dimensional vertical (a) and horizontal wave forces (b) on the rectangular structure

forces decreases significantly with the increases of the evanescent mode and finally tends to be stable at truncation order equal to 6 with fluctuation ratio less than $2 \%$. Therefore, the analytical solutions presented in the following study are restricted by truncating the infinite series at $n=10$ to meet both computational efficiency and accuracy.

Following the determined truncation order and proposed model, the horizontal and vertical wave forces, reflection coefficient, and transmission coefficient of the rectangle structure are calculated. Figure 3 shows the comparisons of reflection coefficient $K_{r}$, transmission coefficient $K_{t}$ and the nondimensional horizontal and vertical wave forces on the rectangle structure between the present study and Mei and Black (1969). In can be found that the calculation results from the present model and the analytical solutions from Mei and Black (1969) are consistent with each other, which indicates that the proposed model of wave force on the rectangle superstructure is reliably, and the proposed model can also estimate the wave properties (reflection and transmission coefficient) accurately.

The second validation case is the experimental test on the 1:30 scale box-girder superstructure under the action of wave forces. This experimental test was conducted in the wave flume at Southwest Jiaotong University in China. As can be seen in Fig. 4, the test specimen was fixed to the middle part of the wave flume by a rigid connection structure and connected with a three-component dynamometer. The offshore approach
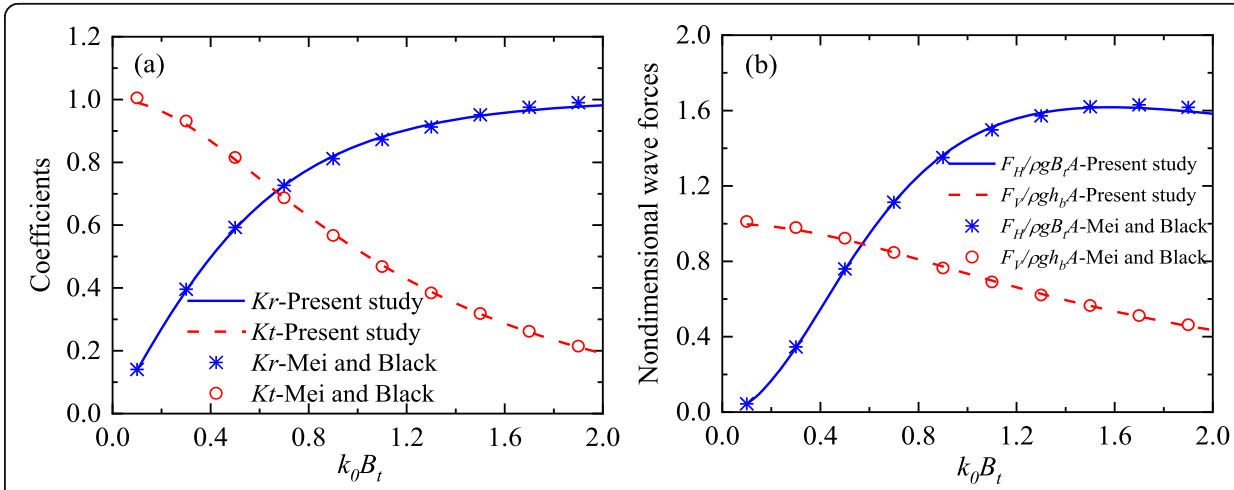

Fig. 3 Comparisons of reflection and transmission coefficients (a) and the nondimensional horizontal and vertical wave forces (b) on the rectangle structure between the present study and Mei and Black (1969) 


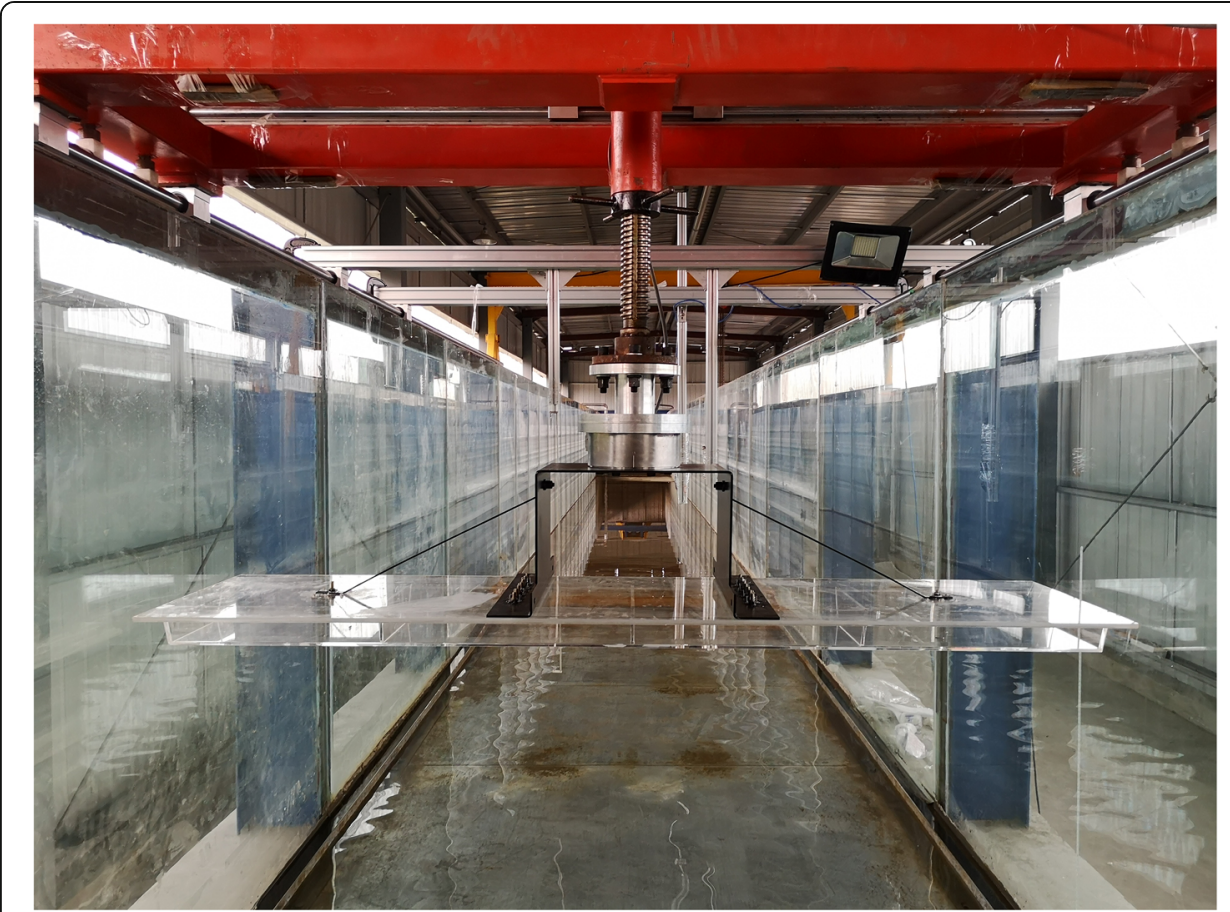

Fig. 4 Box-girder superstructure model investigated in the experimental test (Zhang et al. 2020)

span is simply supported, and the length of the bridge model is $L=1.96 \mathrm{~m}$. According to the experimental wave parameters and the bridge model parameters, the water depth was set as $d=0.713 \mathrm{~m}$, the thickness of bridge deck $h_{t}=0.015 \mathrm{~m}$, the height of the boxgirder superstructure $h_{b}=0.09 \mathrm{~m}$, the half-width of the bridge deck $B_{t}=0.25 \mathrm{~m}$, and the half-width of box-girder $B_{b}=0.128 \mathrm{~m}$. The detail of the experimental setup can be found in the study conducted by Zhang et al. (2020).

The influences of several submergence coefficients $C_{s}$, wave heights $H$, wave periods $T$, and current velocities $V$ on the wave forces on the box-girder superstructure was conducted by the experimental tests. The submergence coefficients $C_{s}=y / h_{b}$, where $y$ represents the submerged depth of the box-girder superstructure. The experimental results for the submerged state $C_{s}=1$ of the box-girder superstructures are chosen for the validation of the proposed potential flow model (the water depth is set as $d=0.713 \mathrm{~m}$ ). Four different wave heights from $0.033 \mathrm{~m}$ to $0.133 \mathrm{~m}$ with an interval of $0.033 \mathrm{~m}$ and four different wave periods of $0.949,1.314,1.68$, and 2.045 were conducted in the test with the submergence coefficients $C_{s}=1$. The 3-component dynamometer with the sampling frequency of $50 \mathrm{~Hz}$ was used to measure the wave forces on the bridge model, and the test results are presented in normalized forms. In addition, four kinds of wave forces are considered in this case, including the nondimensional maximum vertical wave forces $\left(F_{V \max } / \rho g B_{t} A\right)$, minimum vertical wave forces $\left(F_{V \min } / \rho g B_{t} A\right)$, maximum horizontal wave forces $\left(F_{\text {Hmax }} /\right.$ $\left.\rho g h_{b} A\right)$, and minimum horizontal wave forces $\left(F_{H \text { min }} / \rho g h_{b} A\right)$.

Figure 5 shows a comparison of the analytical solutions and experimental results. The analytical solutions of the non-dimensional maximum and minimum vertical wave forces on the box-girder have the same trend as the experimental results, and the values are close to each other from Fig. 5(a) and (b). The maximum vertical force test results are slightly smaller than the analytical solutions when $k_{0} B_{t}<1$, and the analytical 


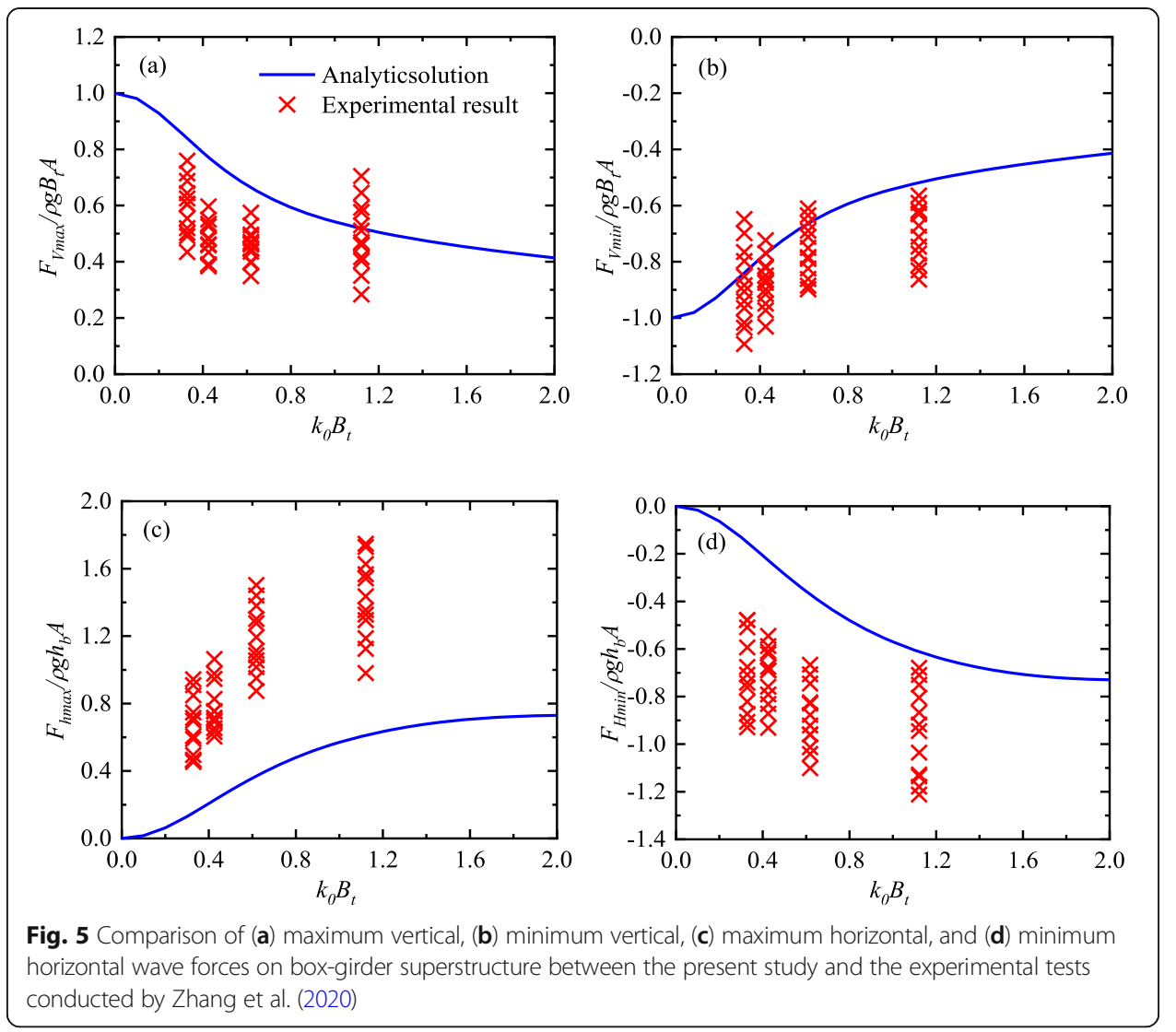

and experimental results are in good agreement when $k_{0} B_{t}>1$. At the same time, for the test conditions with a large wave number, the experimental results fluctuate greatly. Compared with the maximum vertical force, the analytical calculation results of minimum vertical force are more consistent with the experimental results. By analyzing the above trends through experimental phenomena and analytical methods, it can be found that the wave overtopping happens when the wave acting on the box-girder under submerged conditions and further induces the decrease of maximum vertical wave forces. However, the integral range of the vertical wave force on the box-girder does not include the upper boundary of the bridge deck in the analytical calculation, so the maximum vertical force is overestimated. The analytical solutions of nondimensional horizontal forces are generally smaller than the test results, and the minimum horizontal force is more consistent with the test result than the maximum horizontal force (Fig. 5(c) and (d)). The horizontal impulse wave forces on the web of box-girder cannot be calculated by potential flow theory, but the research conducted by Huang et al. (2018a) pointed out that the impact force plays a certain proportion in the horizontal wave force due to the blocking effect of the empty part of the box-girder. Therefore, the horizontal wave forces on the box-girder calculated by the proposed method are smaller than the experimental results. It is should be noted that the deviation exists between the analytical solutions and experimental results may also due to other effects, such as experimental errors, nonlinear effect, and model simplification effect. Generally speaking, the calculation results based on the potential flow theoretical model can reasonably predict the wave forces on the box-girder superstructure. 


\section{Results and discussion}

\subsection{Effect of the girder type}

Since a large number of coastal bridges were destroyed in the coastal area of the Gulf of Mexica during Hurricane Ivan and Katrina, the wave forces and vulnerability analysis of coastal bridges under the action of extreme waves have been investigated. Different from the box-girder superstructures studied in this paper, the previous research has paid more attention to the superstructure with T-type girders commonly seen along with the coastal areas of the United States (Hayatdavoodi et al. 2015; Qu et al. 2017; Fang et al. 2019a). Guo et al. (2015b) estimated the wave forces acting on the submerged bridge superstructure with T-type girders during a hurricane based on the potential flow method. They gave a comprehensive study on the calculation of maximum wave forces on the superstructure, and the comparison of wave forces between the analytical solution and the AASHTO model. However, the box-girder superstructure widely used in the long-span coastal bridges is quite different from the T-type superstructure in structure type, and the flow field and the wave forces for these two superstructures will also be different under the action of extreme waves. In recent years, researches on the wave forces of box-girder superstructures have found that the calculation methods and empirical formulas applicable to the extreme wave forces on T-girder superstructures cannot be directly applied to the calculation of extreme wave forces on box-girder superstructures. Based on the proposed analytical method, the effect of the girder type (T-girder and box-girder) is studied in this subsection. The wave forces on the T-type girders calculated by Guo et al. (2015b) are used to compare with the wave forces on the box-girder superstructure that can be estimated by the proposed analytical method. Additionally, the determination of structural parameters of the box-girder in this comparison should ensure that the two types of superstructures have the same width of the bridge deck and the girder height. Therefore, the parameters of box-girder superstructure are set as $h_{t}=0.03 \mathrm{~m}, h_{b}=0.17 \mathrm{~m}, B_{t}=0.5 \mathrm{~m}$, $B_{b}=0.25$ and $d=1.345 \mathrm{~m}$.

Figure 6 shows the comparison of wave forces between T-girder and box-girder, and it can be seen that different girder types under wave action have a greater influence on the wave forces. According to the dispersion relation of linear waves, the $k_{0} B_{t}$ value of the $\mathrm{x}$-coordinate is a nondimensional parameter related to the wave period. The maximum horizontal wave forces on the two superstructures all present the trend of increase with the increases of $k_{0} B_{t}$ when $k_{0} B_{t}<1$. However, the maximum horizontal wave forces on the T-girder present a sharp increase when $k_{0} B_{t}<1$, reaches the peak when the $k_{0} B_{t}$ value is equal to 1 , and decrease slowly when $k_{0} B_{t}>1$. The maximum horizontal wave force on the T-girder is larger than that on the box-girder with the same $k_{0} B_{t}$ value. This phenomenon is related to the different shapes of two girders, it could be concluded that the waves are directly acting on the web of the Tgirder due to the short flange of the T-girder. $\mathrm{Bu}$ in the case of the box-girder, the front part of the deck flange is interacting with waves firstly, and then waves acting on the girder web with waves propagate. The wave that interacts with the web of the box-girder decreases with wave propagation and diffraction, and finally resulting in the maximum horizontal wave force of the box-girder is smaller than that of the T-girder. In addition, with the increase of $k_{0} B_{t}$ the horizontal wave forces on the box-girder always present an increasing trend, which indicates that the influence of the wave period on the wave force of the box-girder will gradually reduce with the decrease of the wave period. 

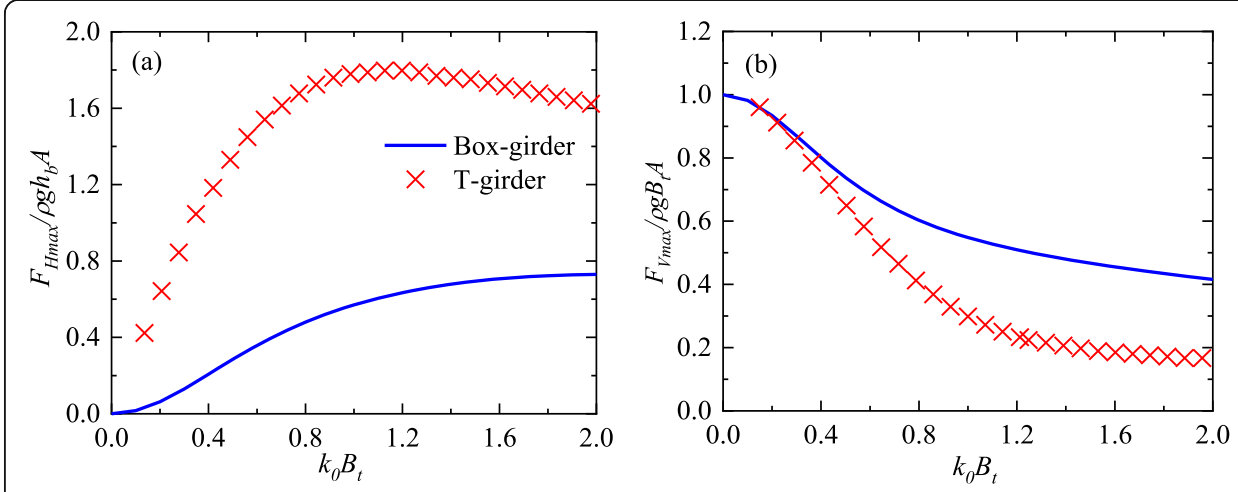

Fig. 6 Comparison of wave forces on T-girder from Guo et al. (2015b) and wave forces on box-girder superstructure calculated by the proposed method

As shown in Fig. 6(b), the maximum vertical wave forces on the two superstructures are nearly the same when $k_{0} B_{t}<0.3$. It is shown that when the wave period and wavelength are large, the superstructure shape has no influence on the wave forces, mainly because the drag force and wake effect are ignored in the analytical calculation, the influence of the girder shape on the wave load can be ignored. The maximum vertical wave force on the $\mathrm{T}$-girder decreases more rapidly than that on the box-girder when $k_{0} B_{t}>0.3$, and gradually trend to stable for the wave forces on the two superstructures when $k_{0} B_{t}>1.6$. The maximum vertical wave force on the T-girder is smaller than that on the box-girder when $k_{0} B_{t}>0.3$. This phenomenon is mainly since the deck bottom and the web bottom of the box-girder always under the wave actions, while the velocity potential between $\mathrm{T}$-girder and waves is small due to the existence of girder gaps. Huang et al. (2018a) conducted a study on the hurricane-induced wave forces on the box-girder and $\mathrm{T}$-girder, and the comparison of wave forces between $\mathrm{T}$-girder and boxgirder in the submerged state were investigated in their study using OpenFOAM. The results show that the maximum horizontal wave force on the T-girder is greater than the wave force on the box-girder, and the maximum vertical wave force on the T-girder is smaller than that on the box-girder under the submerged state, which is consistent with the calculation results of this study. At the same time, compared with the time-consuming pretreatment and programming calculation in the numerical simulation, the proposed analytical method for the wave forces on the coastal bridge superstructures based on the potential flow theory is more efficient and simpler.

\subsection{Effect of the structural configuration}

The structural parameters are also important factors that affect the wave force on the box-girder superstructures, thus the relationship of wave forces on box-girder and the structural configuration is discussed in the following. Based on the proposed analytical method, the influences of the relative width of the girder $L=B_{b} / B_{t}$, the relative thickness of the deck $W=h_{t} / h_{b}$, the relative width of the deck $Z=B_{t} / d$, and the relative height of the box-girder superstructure $D=h_{b} / d$ on the wave forces of the box-girder superstructure are investigated. It should be noted that the four dimensionless parameters include the main factors related to the structural configuration of the box-girder 
superstructure, and the parameter values cover the main range of the size of the boxgirder superstructure.

Figure 7 illustrates the effect of the relative width of the girder $L$ on the wave forces of the box-girder superstructure. It is shown that the variation trends of the maximum vertical and horizontal wave forces are similar to the increase of $k_{0} B_{t}$ under different conditions of $L$. The vertical wave force decreases with the increase of the relative width of the girder, and the relative width of the girder has a smaller effect on the vertical wave forces with large wave periods than that with small wave periods. Compared with the maximum vertical force, the horizontal wave force increases obviously with the increase of $L$, and the amplifications are similar under different wave period conditions. Through analyzing the potential function and boundary conditions of the flow field using the potential flow theory method, the main reason for these phenomena is that the increase of the width of the web leads to the decrease of the space between the flange and the web, and the interference effect of the flange on the flow field is reduced. The conversion of the horizontal velocity component caused by the wave impulse on the flange is negligible because the impulse effect is small with the submerged condition of box-girder superstructures. With the decrease of $L$, the width of the region $\Omega_{2}$ below the flange increases, and further increase the wave propagation distance to the web of the box girder. Besides, the interference of the flange will result in the attenuation of the horizontal velocity component of the flow field with the propagation distance. Therefore, the horizontal maximum wave forces increase with the decreases of $L$. At the same time, as the depth of the water increases, the vertical wave velocity component decreases, resulting in a larger vertical wave force acting on the bottom of the deck than on the bottom of the girder. Therefore, the increase of $L$ leads to a decrease in the width of the bottom of the deck that is subjected to vertical wave forces, which further leads to the reduction of vertical wave forces.

Figure 8 shows that nondimensional vertical wave forces decreasing with the increase of $k_{0} B_{t}$ and the effect of the relative thickness of the deck on the vertical wave forces is increase with the increase of $k_{0} B_{t}$. For $k_{0} B_{t}<1.2$, the maximum horizontal wave forces increase with the increase of $k_{0} B_{t}$ and reach the peak value of horizontal wave force when the wave number approximately 1.2. Additionally, the box-girder superstructure with a higher $W$ experiences a larger horizontal wave force, and differences of horizontal wave forces among these superstructures with different $W$ reaches the highest value when the wave number approximately 1.2. Furthermore, the box-girder superstructure
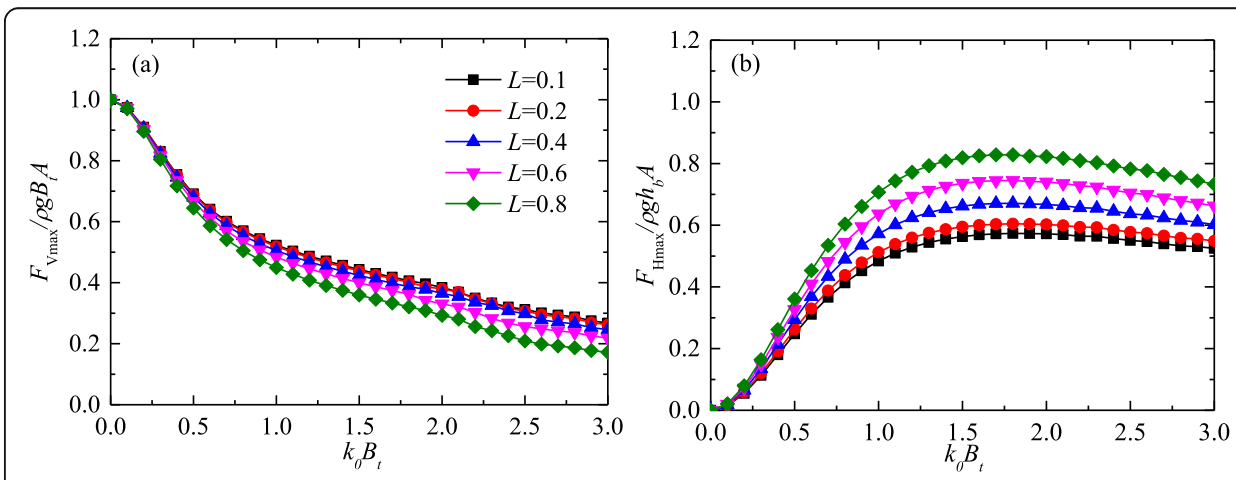

Fig. 7 Influence of the relative width of the girder on the wave forces of the box-girder superstructure 

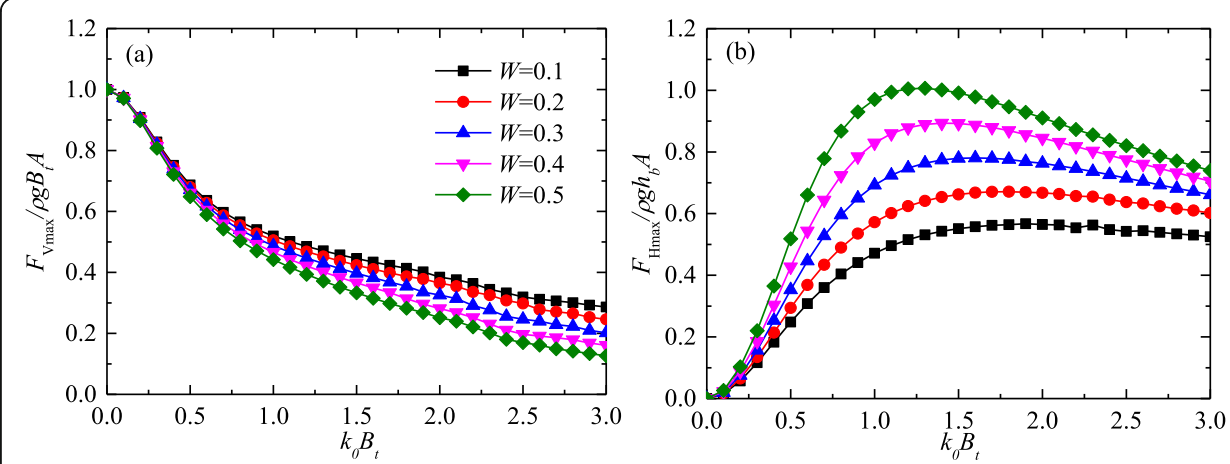

Fig. 8 Influence of the relative thickness of the deck on the wave forces of the box-girder superstructure

with a higher $W$ endures a higher distance from the bottom of the deck to the still water level, the vertical velocity component of water particle around the bottom of the deck will decrease and further results in the decrease of the maximum vertical wave forces. The relative thickness of the deck affects the horizontal wave forces on the front of the deck and the web of the girder and a strong reflection caused by a higher deck thickness will result in larger horizontal wave forces on the front of the deck.

The effect of the relative height of the box-girder on the wave forces of the boxgirder superstructure is shown in Fig. 9. The height of the box-girder increases with the increase of the relative height $D$ of the box-girder under the condition of constant water depth, which changes the relative position relation between the box-girder and the flow field. With the increase of $D$, although the width of the box-girder and the stressed area in the vertical direction do not change, the deck and web of the box girder structure are close to the bottom, so the vertical wave force acting on the box-girder is significantly reduced. Under the condition of the different relative height of the boxgirder height, the variation trend of dimensionless maximum horizontal forces with wave number $k_{0} B_{t}$ is different. When the relative height of the box-girder is small ( $D=$ 0.1 ), that is, the bottom of the box-girder is far away from the water bottom, the dimensionless horizontal force increases with the increase of wave number and becomes stable after wave number equal to 2.0. Then, with the increase of the relative height, the dimensionless horizontal wave force increases first and then decreases with $k_{0} B_{t}$. As a result, the dimensionless horizontal force increases with the increase of $D$ for the
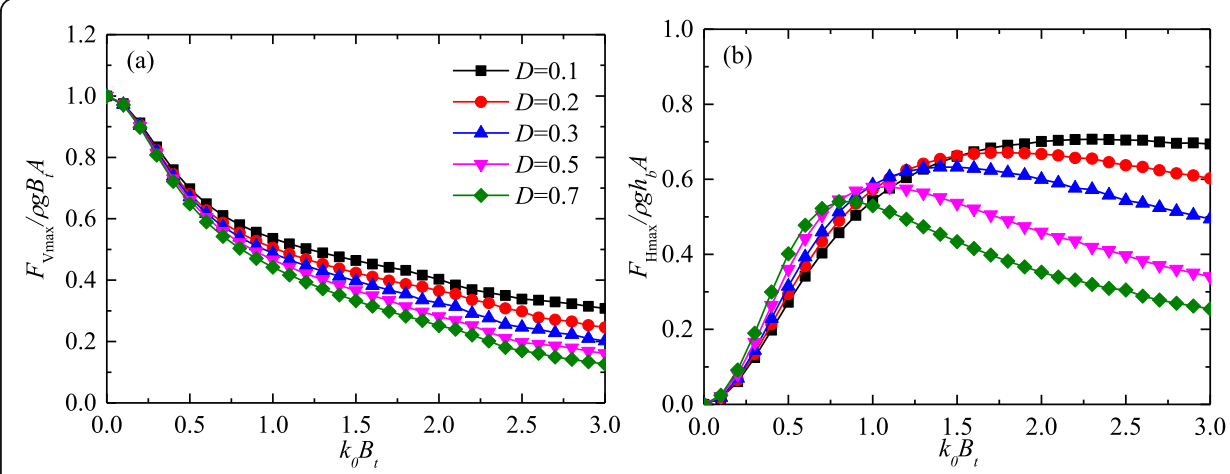

Fig. 9 Influence of the relative height of the box-girder on the wave forces of the box-girder superstructure 
large wave period condition and decreases with the increase of $D$ for the small wave period condition.

As shown in Fig. 10, the influence of the relative width of the deck on the wave forces of the box-girder superstructure is conducted using the proposed method. The dimensionless vertical force on the box-girder structure is greatly affected by the relative width of the deck, the smaller $Z$ results in a smaller dimensionless maximum vertical force, and the decreasing trend becomes more and more obvious with the decreasing of $Z$. With the increase of $Z$, the area that suffered the wave action in the vertical direction increases, and further leads to the increase of the vertical wave force. Under the condition of the different relative width of the deck, the variation trend of dimensionless horizontal forces with wave number is also significantly different, which is just opposite to the trend of the relative height of the box-girder shown in Fig. 9(b). This phenomenon may be related to the ratio of wavelength to the width of the box-girder superstructure. As a result, the dimensionless horizontal force tends to increase with the increase of relative flange width under the condition of a small wave period and decrease under the condition of a large wave period. The wave number corresponding to the peak value of the horizontal wave forces for various relative width of the deck is in the range of 1.0 to 1.5 .

In general, the effect of two nondimensional parameters (relative width of the girder and relative thickness of the deck) of the box-girder superstructures on maximum wave forces is similar. In other words, the increase of the two parameters results in the decrease of the dimensionless vertical force and the increase of the dimensionless horizontal force. For the remaining two dimensionless structure dimension parameters, their influences on wave forces are quite different. It can be concluded that in the safety design of the box-girder superstructure considering the action of wave forces, the influence of multiple structural dimension parameters should be considered comprehensively.

\section{Conclusions}

The analytical method to estimate the wave forces on the box-girder superstructures in the submerged condition is proposed based on the potential flow theory and matching eigenfunction method in this paper. The accuracy and efficiency of the proposed analytical method are validated by the classical problem studied by Mei and Black (1969) and the hydrodynamic experiment conducted on the box-girder superstructure. Further
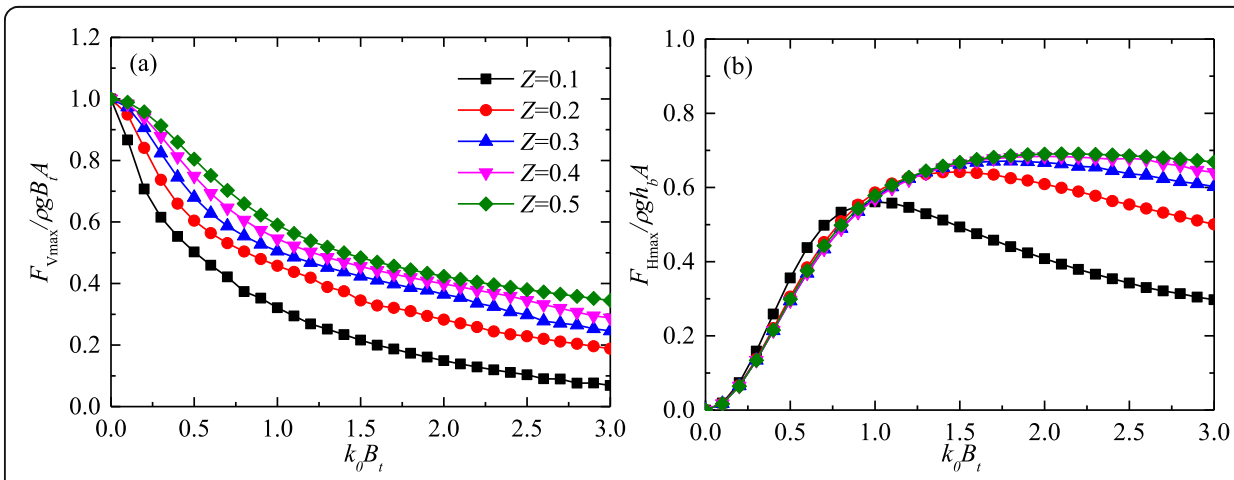

Fig. 10 Influence of the relative width of the deck on the wave forces of the box-girder superstructure 
investigation about the influences of the girder type and structural configuration on the wave forces of the box-girder superstructures are conducted using the proposed method. Based on the investigations, the following conclusions are reached:

(1) The proposed analytical method based on the potential flow theory and matching eigenfunction method is efficient and accurate in calculating the wave forces on the box-girder superstructure in the submerged condition.

(2) The girder type has a greater influence on the wave forces on the superstructure of coastal bridges. The maximum horizontal wave force on the T-girder is larger than that on the box-girder with the same $k_{0} B_{t}$ value. The maximum vertical wave forces on the two superstructures are nearly the same when $k_{0} B_{t}<0.3$. The maximum vertical wave force on the T-girder is smaller than that on the box-girder when $k_{0} B_{t}>0.3$.

(3) The effect of four non-dimensional parameters of the box-girder superstructures on maximum wave forces is quite different. The influence of multiple structural dimension parameters should be considered comprehensively in the safety design of the box-girder superstructure considering the action of wave forces.

(4) The analytical method is proposed based on the linear framework, and the interaction between the waves and the box-girder superstructure was ignored in the present study. The three-dimensional analytical model and the effect of structural response on the wave forces of the box-girder superstructure should be conducted in future research.

\section{Appendix}

$$
\begin{aligned}
& f_{n}^{s}=\frac{2}{d-h_{t}} \int_{-d}^{-h_{t}} Z_{0}\left(k_{0} z\right) Y_{1 n}\left(\lambda_{1 n} z\right) \mathrm{d} z \\
& a_{n m}^{s}=\frac{2}{d-h_{t}} \int_{-d}^{-h_{t}} Z_{m}\left(k_{m} z\right) Y_{1 n}\left(\lambda_{1 n} z\right) \mathrm{d} z \\
& e_{n}^{s}=\left\{\begin{array}{cc}
-1 & (n=0) \\
0 & (n=1,2, \cdots, N)
\end{array}\right. \\
& b_{m n}^{s}=\left\{\begin{array}{cc}
0 & (m=1,2, \cdots N, n=0) \\
-i \lambda_{1 n} \tanh \lambda_{1 n} B_{t} \int_{-{ }^{d}}^{-h_{t}} Z_{0}\left(k_{0} z\right) Y_{1 n}\left(\lambda_{1 n} z\right) \mathrm{d} z / k_{0} \int_{-d}^{-h_{t}} Z_{0}^{2}\left(k_{0} z\right) \mathrm{d} z & (m=0, n=0,1, \cdots N) \\
\lambda_{1 n} \tanh \lambda_{1 n} B_{t} \int_{-d}^{-h_{t}} Z_{m}\left(k_{m} z\right) Y_{1 n}\left(\lambda_{1 n} z\right) \mathrm{d} z / k_{m} \int_{-d}^{-h_{t}} Z_{m}{ }^{2}\left(k_{m} z\right) \mathrm{d} z & (m, n=1,2, \cdots N)
\end{array}\right. \\
& c_{m n}^{s}=\left\{\begin{array}{cc}
\frac{2}{d-h_{b}} \int_{-d}^{-h_{b}} Y_{10}\left(\lambda_{10} z\right) Y_{2 m}\left(\lambda_{2 m} z\right) \mathrm{d} z & (n=0) \\
\frac{2}{d-h_{b}} \frac{\cosh \lambda_{1 n} B_{b}}{\cosh \lambda_{1 n} B_{t}} \int_{-d}^{-h_{b}} Y_{1 n}\left(\lambda_{1 n} z\right) Y_{2 m}\left(\lambda_{2 m} z\right) \mathrm{d} z & (n=1,2, \cdots, N)
\end{array}\right. \\
& f_{n}^{a}=-\frac{2}{d-h_{t}} \int_{-d}^{-h_{t}} Z_{0}\left(k_{0} z\right) Y_{1 n}\left(\lambda_{1 n} z\right) \mathrm{d} z \\
& a_{n m}^{a}=-\frac{2}{d-h_{t}} \int_{-d}^{-h_{t}} Z_{m}\left(k_{m} z\right) Y_{1 n}\left(\lambda_{1 n} z\right) \mathrm{d} z
\end{aligned}
$$




$$
\begin{aligned}
& e_{n}^{a}=\left\{\begin{array}{cc}
-1 & (n=0) \\
0 & (n=1,2, \cdots, N)
\end{array}\right. \\
& b_{m n}^{a}=\left\{\begin{array}{cc}
i \int_{-d}^{-h_{t}} Z_{0}\left(k_{0} z\right) Y_{10}\left(\lambda_{10} z\right) \mathrm{d} z / k_{0} B_{t} \int_{-d}^{-h_{t}} Z_{0}^{2}\left(k_{0} z\right) \mathrm{d} z & (m, n=0) \\
\int_{-d}^{-h_{t}} Z_{m}\left(k_{m} z\right) Y_{10}\left(\lambda_{10} z\right) \mathrm{d} z / k_{m} B_{t} \int_{-d}^{-h_{t}} Z_{m}^{2}\left(k_{m} z\right) \mathrm{d} z & (m=1,2, \cdots N, n=0) \\
i \lambda_{1 n} \int_{-d}^{-h_{t}} Z_{0}\left(k_{0} z\right) Y_{1 n}\left(\lambda_{1 n} z\right) \mathrm{d} z / k_{0} \tanh \lambda_{1 n} B_{t} \int_{-d}^{-h_{t}} Z_{0}^{2}\left(k_{0} z\right) \mathrm{d} z & (m=0, n=1,2, \cdots N) \\
\lambda_{1 n} \int_{-d}^{-h_{t}} Z_{m}\left(k_{m} z\right) Y_{1 n}\left(\lambda_{1 n} z\right) \mathrm{d} z / k_{m} \tanh \lambda_{1 n} B_{t} \int_{-d}^{-h_{t}} Z_{m}^{2}\left(k_{m} z\right) \mathrm{d} z & (m, n=1,2, \cdots N)
\end{array}\right. \\
& c_{m n}^{a}=\left\{\begin{array}{cc}
\frac{2}{d-h_{b}} \frac{B_{b}}{B_{t}} \int_{-d}^{-h_{b}} Y_{10}\left(\lambda_{10} z\right) Y_{2 m}\left(\lambda_{2 m} z\right) \mathrm{d} z & (n=0) \\
\frac{2}{d-h_{b}} \frac{\sinh _{1 n} B_{b}}{\sinh \lambda_{1 n} B_{t}} \int_{-d}^{-h_{b}} Y_{1 n}\left(\lambda_{1 n} z\right) Y_{2 m}\left(\lambda_{2 m} z\right) \mathrm{d} z & (n=1,2, \cdots, N)
\end{array}\right.
\end{aligned}
$$

\section{Abbreviations}

RANS: Reynolds-averaged Navier-Stokes; VOF: Volume of Fluid; AASHTO: American Association of State Highway and Transportation Officials

\section{Acknowledgments}

Not applicable.

\section{Authors' contributions}

$\mathrm{BH}$ carried out the manuscript writing and numerical analysis, QR provided guidance in methodology development, XC provided guidance in technical writing, JZ carried out the analytical model, and BZ participated in the design of the study. The authors read and approved the final manuscript.

\section{Funding}

The authors are grateful for the support of this research by the National Natural Science Foundation of China $(52008065,41472262,51805057)$, the National natural science foundation of China - China railway corporation highspeed railway basic research joint fund project (U1834207), the Chongqing Municipal Education Commission Science and Technology Research Project (KJQN202000706), the China Postdoctoral Science Foundation (2020 M683229), the Key Project of National Key Research and Development Project (2016YFC0802206-3), the Program for Innovation Team Building at Institutions of Higher Education in Chongqing (CXQT19021), the Major Applied Basic Research Frontier Projects in Sichuan Province (2017JY0003), and the High-Level Technical Personnel Training Project of Transportation Industry.

Availability of data and materials

Data used in the present study will be available upon request.

\section{Competing interests}

The authors declare that they have no competing interests.

\section{Author details}

${ }^{1}$ State Key Laboratory of Mountain Bridge and Tunnel Engineering, Chongqing Jiaotong University, Chongqing 400074 China. ${ }^{2}$ School of Civil Engineering, Chongqing Jiaotong University, Chongqing 400074, China. ${ }^{3}$ School of Mechanotronics \& Vehicle Engineering, Chongqing Jiaotong University, Chongqing 400074, China. ${ }^{4}$ Department of Bridge Engineering, School of Civil Engineering, Southwest Jiaotong University, Chengdu 610031, China.

Received: 23 October 2020 Accepted: 23 November 2020

Published online: 07 December 2020

\section{References}

Bradner C, Schumacher T, Cox D, Higgins C (2011) Large-scale laboratory observations of wave forces on a highway bridge superstructure. OTREC RR-11-10. Transportation Research and Education Center (TREC), Portland

Bricker JD, Nakayama A (2014) Contribution of trapped air, deck superelevation, and nearby structures to bridge deck failure during a tsunami. J Hydraul Eng 140(5):05014002

Cuomo G, Shimosako K, Takahashi S (2009) Wave-in-deck loads on coastal bridges and the role of air. Coast Eng 56(8):793-809

Douglass S, Chen Q, Olsen J, Edge B, Brown D (2006) Wave forces on bridge decks. Final rep for U.S. Dept of transportation, Federal Highway Administration, Office of Bridge Technology, U.S. Dept of transportation, Washington DC

Douglass SL, Krolak J (2008) Highways in the coastal environment. Publication no FHWA-NHI-07-096 Office of Bridge Technology Federal Highway Administration, Washington DC

Fang Q, Hong R, Guo A, Li H (2019a) Experimental investigation of wave forces on coastal bridge decks subjected to oblique wave attack. J Bridg Eng 24(4):04019011 
Fang Q, Hong R, Guo A, Stansby PK, Li H (2018) Analysis of hydrodynamic forces acting on submerged decks of coastal bridges under oblique wave action based on potential flow theory. Ocean Eng 169:242-252

Fang Q, Yang C, Guo A (2019b) Hydrodynamic performance of submerged plates during focused waves. J Marine Sci Eng 7(11):389

Guo A, Fang Q, Li H (2015b) Analytical solution of hurricane wave forces acting on submerged bridge decks. Ocean Eng 108: $519-528$

Guo AX, Fang QH, Bai XD, Li H (2015a) Hydrodynamic experiment of the wave force acting on the superstructures of coastal bridges. J Bridg Eng 20(12):04015012.

Hayashi H (2013) Study on tsunami wave force acting on a bridge superstructure. Proc. 29th US-Japan bridge engineering workshop, Tsukuba

Hayatdavoodi M, Ertekin RC, Robertson IN (2015) Vulnerability assessment of coastal bridges on Oahu impacted by storm surge and waves. Nat Hazards 79(2):1133-1157

Hayatdavoodi M, Seiffert B, Ertekin RC (2014) Experiments and computations of solitary-wave forces on a coastal-bridge deck. Part II: deck with girders. Coast Eng 88:210-228

Huang B, Duan L, Yang Z, Zhang J, Kang A, Zhu B (2019a) Tsunami forces on a coastal bridge deck with a box girder. J Bridg Eng 24(9):04019091

Huang B, Yang Z, Zhu B, Zhang J, Kang A, Pan L (2019b) Vulnerability assessment of coastal bridge superstructure with box girder under solitary wave forces through experimental study. Ocean Eng 189:106337

Huang B, Zhu B, Cui S, Duan L, Cai Z (2018b) Influence of current velocity on wave-current forces on coastal bridge decks with box girders. J Bridg Eng 23(12):04018092

Huang B, Zhu B, Cui S, Duan L, Zhang J (2018a) Experimental and numerical modelling of wave forces on coastal bridge superstructures with box girders, part I: regular waves. Ocean Eng 149:53-77

Istrati D, Buckle I, Lomonaco P, Yim S, Itani A (2016). Large-scale experiments of tsunami impact forces on bridges: the role of fluid-structure interaction and airventing. In: The 26th International Ocean and polar engineering conference. ISOPE; Rhodes.

Istrati D, Buckle IG, Lomonaco P, Yim S, Itani A (2017) Tsunami induced forces in bridges: large-scale experiments and the role of air-entrapment. Coastal Eng Proc 1(35):30

McPherson RL (2008) Hurricane induced wave and surge forces on bridge decks m.Sc. Thesis. Texas A\&M University, College Station

Mei CC, Black JL (1969) Scattering of surface waves by rectangular obstacles in waters of finite depth. J Fluid Mech 38(3):499-511

Motley MR, Wong HK, Qin X, Winter AO, Eberhard MO (2015) Tsunami-induced forces on skewed bridges. J Waterw Port Coast Ocean Eng 142(3):04015025

Motley MR, Wong HK, Qin X, Winter AO, Eberhard MO (2016) Tsunami-induced forces on skewed bridges. J Waterway, Port, Coastal, Ocean Eng 142(3):04015025

Qu K, Sun WY, Kraatz S, Deng B, Jiang CB (2020) Effects of floating breakwater on hydrodynamic load of low-lying bridge deck under impact of cnoidal wave. Ocean Eng 203:107217

Qu K, Tang HS, Agrawal A, Cai Y (2017) Hydrodynamic effects of solitary waves impinging on a bridge deck with air vents. J Bridg Eng 22(7):04017024

Qu K, Tang HS, Agrawal A, Cai Y, Jiang CB (2018) Numerical investigation of hydrodynamic load on bridge deck under joint action of solitary wave and current. Appl Ocean Res 75:100-116

Seiffert BR, Ertekin RC, Robertson IN (2014) Experimental investigation on the role of entrapped air on solitary wave forces on a coastal bridge deck. In: Proc. 33rd Int. Conf. On ocean, offshore and Arctic engineering, OMAE'14. ASME, San Francisco

Shoji G, Moriyama T (2007) Evaluation of the structural fragility of a bridge structure subjected to a tsunami wave load. J Nat Dis Sci 29(2):73-81. https://doi.org/10.2328/jnds.29.73

Xiao H, Huang WR, Chen Q (2010) Effects of submersion depth on wave uplift force acting on Biloxi Bay bridge decks during hurricane Katrina. Comput Fluids 39(8):1390-1400

Xu G, Cai CS (2014) Wave forces on Biloxi bay bridge decks with inclinations under solitary waves. J Perform Constr Facil 29(6):1-13

Xu G, Cai CS (2015) Numerical simulations of lateral restraining stiffness effect on bridge deck-wave interaction under solitary waves. Eng Struct 101:337-351

Xu G, Cai CS (2017) Numerical investigation of the lateral restraining stiffness effect on the bridge deck-wave interaction under stokes waves. Eng Struct 130:112-123

Xu G, Cai CS, Chen Q (2016a) Countermeasure of air venting holes in the bridge deck-wave interaction under solitary waves. J Perform Constr Facil 31(1):04016071

Xu G, Cai CS, Deng L (2016b) Numerical prediction of solitary wave forces on a typical coastal bridge deck with girders. Struct Infrastruct Eng 13(2):254-272

Xu G, Chen Q, Zhu L, Chakrabarti A (2017) Characteristics of the wave loads on coastal low-lying twin-deck bridges. J Perform Constr Facil 32(1):04017132

Yeh H, Francis M, Prterson C, Katada T, Latha G, Chadha RK, Singh JP, Raghuraman G (2007) Effects of the 2004 great Sumatra tsunami: southeast Indian coast. J Waterw Port Coastal Ocean Eng 133(6):382-400

Zhang J, Zhu B, Kang A, Yin R, Li X, Huang B (2020) Experimental and numerical investigation of wave-current forces on coastal bridge superstructures with box girders. Adv Struct Eng 23(7):1438-1453

Zhu M, Elkhetali I, Scott MH (2018) Validation of OpenSees for tsunami loading on bridge superstructures. J Bridg Eng 23(4): 04018015

\section{Publisher's Note}

Springer Nature remains neutral with regard to jurisdictional claims in published maps and institutional affiliations. 